\title{
The effect of breathing and skin stimulation techniques on labour pain perception of Turkish women
}

\author{
Gulay Yildirim MSc, Nevin Hotun Sahin PhD
}

G Yildirim, NH Sahin. The effect of breathing and skin stimulation techniques on labour pain perception of Turkish women. Pain Res Manage 2004;9(4):183-187.

OBJECTIVE: To determine the effect of breathing techniques and nurse-administered massage on the pain perception of pregnant woman during labour.

SETTING AND PARTICIPANTS: The present study was conducted among pregnant women (75\% primiparous) admitted to the SSK Bakirkoy Women and Children's Hospital (Istanbul, Turkey) between January 1, and September 1, 2000. The patients were in their 38 th to 42 nd week of pregnancy, not at high risk and expected to have normal vaginal delivery. They were selected from volunteers by nonrandom sampling.

STUDY DESIGN: The present study involved 40 cases, with 20 in the experimental group and 20 in the control group. Data were obtained through the visual analogue scale, inspection form, observation form and postnatal interview form. The study investigators provided information about labour, breathing techniques and massage to the pregnant women assigned to the experimental group at the beginning of labour (latent phase). A study investigator also accompanied them during labour. These women received nurse-administered massage and were encouraged to breathe and perform self-administered massage. They were also instructed to change their positions and to relax.

RESULTS AND CONCLUSION: Study results demonstrated that nursing support and patient-directed education concerning labour and nonpharmacological pain control methods (eg, breathing and cutaneous stimulation techniques) were effective in reducing the perception of pain by pregnant women (when provided in the latent labour phase before delivery), leading to a more satisfactory birth experience.

Key Words: Labour experience; Labour pain; Supportive nursing care; VAS; Visual analogue scale
L'effet des techniques de respiration et de stimulation cutanée sur la perception de la douleur de femmes turques pendant le travail

OBJECTIF : Déterminer l'effet de techniques de respiration et d'un massage administré par l'infirmière sur la perception de la douleur de femmes enceintes pendant le travail.

ÉTABLISSEMENT ET PARTICIPANTES : La présente étude a été menée parmi des femmes enceintes (75\% de primipares) hospitalisées à l'hôpital mère-enfant SSK Bakirkoy (Istanbul, Turquie) entre le $1^{\text {er }}$ janvier et le $1^{\text {er }}$ septembre 2000. Les patientes avaient atteint de 38 à 42 semaines d'une grossesse à faible risque et avaient prévu un accouchement vaginal normal. Elles ont été sélectionnées parmi un échantillonnage non aléatoire de volontaires.

CONCEPTION DE L'ÉTUDE : La présente étude portait sur 40 cas, 20 faisant partie du groupe expérimental et 20, du groupe témoin. Les données ont été obtenues au moyen d'une échelle analogique visuelle, d'un formulaire d'inspection, d'un formulaire d'observation et d'un formulaire d'entrevue postnatale. Les investigateurs ont fourni de l'information au sujet du travail, des techniques de respiration et du massage aux femmes enceintes du groupe expérimental en début de travail (phase latente). L'un des investigateurs les a également accompagnées pendant le travail. Ces femmes ont reçu un massage donné par une infirmière et ont été encouragées à respirer et à s'auto-administrer des massages. Elles ont également été invitées à changer de position et à se détendre.

RÉSULTATS ET CONCLUSION : Les résultats de l'étude ont démontré que le soutien infirmier et l'éducation des patients au sujet du travail et des méthodes non pharmacologiques de contrôle de la douleur (p. ex., respiration et techniques de stimulation cutanée) étaient efficaces pour réduire la perception de la douleur par les femmes enceintes (lorsqu'elle était transmise pendant la phase de latence, avant l'accouchement), ce qui favorisait une expérience d'accouchement plus satisfaisante.
T abour is an important life event. Technological advances Land obstetric developments have made delivery safer for both the mother and the baby (1). Favourable delivery experiences for the mother and family-centred approaches to labour have gained popularity. In addition to providing a safe delivery for both the baby and the mother, the current focus of care during labour also aims to achieve a favourable and satisfactory delivery experience $(2,3)$.

Every woman has concerns about labour, the most important of which is coping with labour pain. In addition, recent studies have demonstrated that women who think positive thoughts about the delivery are better able to cope with labour pains $(1,4-6)$.

Pregnant women usually do not have sufficient knowledge about childbirth and postpartum care $(6,7)$. Their knowledge is incomplete and full of exaggerations. Thus, the delivery is awaited with fear, anxiety and a lack of confidence (7). For this reason, pregnancy education classes (childbirth classes) have been opened in many countries to fulfill the educational requirements of candidate parents. In these classes, essential knowledge is given about labour and distressing situations that may be experienced during labour, as well as advice on how to cope with 
labour pain (6). Men also participate in these programs and are taught how to encourage and support their pregnant partners. One of the major issues in childbirth classes is how to cope with labour pain. Both pharmacological and nonpharmacological methods are taught $(6,8)$. Nonpharmacological pain relief methods, including breathing, massage, imagery and relaxation, are used frequently during labour $(9,10)$. Research findings have demonstrated that massage has especially positive effects on coping with labour pain (10-12). Research in one-on-one care and touch support from husbands/partners, nurses, nurse-midwives, and doulas or midwives during labour, has shown that such interventions result in shorter labour and lower rates of epidural anesthesia and cesarean section deliveries (13-15). Also, a smaller percentage of the newborns are admitted to neonatal intensive care units and/or experience fetal distress. Women who receive massage from their husbands or partners during labour experience shorter labour times (13).

The time period from the second trimester up to a few weeks before delivery is a suitable time in which to teach nonpharmacological pain control methods that are especially effective in controlling labour pain. In addition, these nonpharmacological methods can be taught to women arriving at the maternity unit without any preparation. The latent labour phase is the ideal time for this instruction. Because labour during the latent phase is much less painful, pregnant women can concentrate more effectively and the education provided can be understood more easily $(6,7)$.

In Turkey, $67 \%$ of pregnant women receive prenatal care (16). This statistic includes women who receive prenatal care at least once before they give birth. Only 33\% of pregnant women insist on prenatal care (16). Prenatal classes are not widespread in Turkey and they exist only in urban centres. Even during these classes, pregnant women are not effectively informed about labour pain or methods of pain control. Therefore, most pregnant women enter hospitals to give birth with no information about labour pain (7). In addition, epidural analgesia is not widespread in Turkey and it is only available in some urban hospitals (17).

The purpose of the present study was to determine the effects of breathing and skin stimulation techniques performed during labour on pregnant women's perception of pain.

\section{METHODS}

\section{Sample}

The present study was conducted with primiparous pregnant women admitted to the SKK Bakirkoy Women and Children's Hospital (Istanbul, Turkey) between January 1, and September 1, 2000. The women were selected from volunteers by nonrandom sampling. They were in their 38 th to 42 nd week of pregnancy, at low risk, in the latent phase of labour and expected to have normal vaginal delivery. Of the 40 enrolled women, 20 were placed in the experimental group and 20 were placed in the control group. Permission was granted from the hospital's ethics committee and all women gave informed consent to participate.

Approximately 50 vaginal deliveries occur per day at SSK Bakirkoy Women and Children's Hospital. Pregnant women are accepted to the maternity unit after cervix dilation reaches $2 \mathrm{~cm}$. The pregnant women's partners are not allowed into the maternal unit and do not see their partners until $4 \mathrm{~h}$ after delivery. All pregnant women stay in the same room until cervical dilation is completed. Because of the insufficient number of midwives and nurses, nursing support is not offered when dealing with labour pain.

\section{Data collection}

A single researcher attended and collected data in the present study. The demographic and obstetric characteristics of the pregnant woman were entered into the observation form, including the visual analogue scale (VAS) values, applications used, duration of the delivery, and the sex and weight of the baby. This form also included observational records on the emotional behaviour displayed by the pregnant women in the control and experimental groups during the active phase. The experimental and control group mothers' thoughts about labour pain, the labour room and the delivery process, along with some remarks regarding their current feelings, were recorded in the postnatal interview form. The VAS was composed of a paper ruler with numbers ranging from zero to 10 , with a colour display over the numbers ranging from white (zero) to dark red (10). In addition, a mobile pointer was included inside the ruler to indicate the numerical value on the ruler. "No pain" was graded as zero and "the most severe pain" was graded as 10 .

\section{Procedure}

The study investigators provided information about labour, breathing techniques and massage to the pregnant women assigned to the experimental group in the latent phase of labour, and accompanied these women during labour. The women received nurse-administered massage and were encouraged to perform breathing exercises and self-administered massage. They were also instructed to change their positions and to relax. Slow, deep inhalations were encouraged in the latent phase and rapid, shallow breathing was encouraged in the active phase. Finally, the pant-blow abdominal breathing technique was applied in the second stage of labour. In addition, lower and upper back massages were administered to the pregnant women by a nurse. The women were also instructed to give themselves a soft massage in the abdominal area using their fingers. The pregnant women assigned to the control group were monitored routinely in the labour room and did not receive education or supportive nursing care. In both the experimental and control groups, pregnant women were asked to express the severity of pain experienced at $2 \mathrm{~cm}, 4 \mathrm{~cm}, 6 \mathrm{~cm}$, $8 \mathrm{~cm}$ and $10 \mathrm{~cm}$ of cervical dilation. In the active phase of dilation, the pregnant women in the control and experimental groups were observed and their behaviours were classified by the study investigator. These notes were then recorded on the observation form. The postnatal interview form was filled out face-to-face in the delivery room within $2 \mathrm{~h}$ after delivery. The results for informative characteristics, dilation periods and interview after birth were compared by percentage means, $\chi^{2}$ and Fisher's exact test. The Student's $t$ test was used in independent groups to examine differences in dilation periods.

\section{RESULTS}

The average age of mothers was 22.25 years ( $\mathrm{SD}=3.6$ years) in the control group and 22.85 years $(\mathrm{SD}=3.0$ years) in the experimental group. In the control group, $65 \%$ of women had eight years of education and $35 \%$ had 11 years of education. In the experimental group, $85 \%$ of women had eight years of education and $15 \%$ had 11 years of education. The educational level of women in the experimental and control groups were found to be similar $\left(\chi^{2}=2.13, \mathrm{P}=0.275\right)$. A large proportion of the mothers had planned pregnancies. Seventy-five per cent of control group mothers, and all of the mothers in the experimental group, were prima gravida. When examined for labour preparation, it was found that most mothers did not participate 
TABLE 1

Characteristics of control and experimental groups

\begin{tabular}{|c|c|c|c|c|c|c|c|c|}
\hline & \multicolumn{2}{|c|}{$\begin{array}{c}\text { Control group } \\
(n=20)\end{array}$} & \multicolumn{2}{|c|}{$\begin{array}{c}\text { Experimental group } \\
(\mathrm{n}=20)\end{array}$} & \multicolumn{2}{|c|}{$\begin{array}{c}\text { Total } \\
(n=40)\end{array}$} & $\chi^{2}$ & $\mathbf{P}$ \\
\hline \multicolumn{9}{|l|}{ Education (total years) } \\
\hline 11 years & 7 & 35 & 3 & 15 & 10 & 25.0 & & \\
\hline Planned pregnancy & 18 & 90 & 16 & 80 & 34 & 87.5 & 0.784 & 0.661 \\
\hline 1 & 15 & 75 & 20 & 100 & 35 & 87.5 & 5.717 & 0.057 \\
\hline 2 & 4 & 20 & - & - & - & - & & \\
\hline 3 & 1 & 5 & - & - & - & - & & \\
\hline \multicolumn{9}{|c|}{ Prenatal education program } \\
\hline Attended & 2 & 10 & - & - & 2 & 5.0 & 2.105 & 0.487 \\
\hline \multicolumn{9}{|c|}{ Reading publications about birth } \\
\hline
\end{tabular}

TABLE 2

Comparison of mothers' emotional behaviour during labour between control and experimental groups

\begin{tabular}{|c|c|c|c|c|c|c|c|c|}
\hline \multirow[b]{2}{*}{ Emotional behaviour } & \multicolumn{2}{|c|}{$\begin{array}{c}\text { Control group } \\
(n=20)\end{array}$} & \multicolumn{2}{|c|}{$\begin{array}{l}\text { Experimental group } \\
\qquad(n=20)\end{array}$} & \multicolumn{2}{|c|}{$\begin{array}{c}\text { Total } \\
(n=40)\end{array}$} & \multirow[b]{2}{*}{$\chi^{2}$} & \multirow[b]{2}{*}{$\mathbf{P}$} \\
\hline & $\mathbf{n}$ & $\%$ & $\mathbf{n}$ & $\%$ & $\mathbf{n}$ & $\%$ & & \\
\hline Loud crying & 16 & 80 & - & - & 16 & 40.0 & 23.438 & 0.000 \\
\hline Changing of facial expressions & 20 & 100 & 9 & 45 & 29 & 72.5 & 12.539 & 0.000 \\
\hline Complaining & 16 & 80 & 4 & 20 & 20 & 50.0 & 12.100 & 0.000 \\
\hline Screaming & 11 & 55 & - & - & 11 & 27.5 & 12.539 & 0.000 \\
\hline An expression of fear & 9 & 45 & 1 & 5 & 10 & 25.0 & 8.533 & 0.008 \\
\hline Sensitivity & 13 & 65 & 2 & 10 & 15 & 37.5 & 12.907 & 0.001 \\
\hline Grasping of objects & 15 & 75 & 5 & 25 & 20 & 50.0 & 8.100 & 0.004 \\
\hline Uneasiness & 9 & 45 & 2 & 10 & 11 & 27.5 & 4.514 & 0.031 \\
\hline Grasping movement & 17 & 85 & 10 & 50 & 27 & 67.5 & 4.103 & 0.041 \\
\hline
\end{tabular}

in educational programs $\left(\chi^{2}=2.105, \mathrm{P}>0.05\right)$. The majority of patients had not read any published information about birth $\left(\chi^{2}=0.535, \mathrm{P}>0.05\right)$. It was also observed that both groups were similar in their reading of published information about birth (Table 1), with no difference between groups.

When the emotional behaviour of mothers during the active phase was recorded, features such as loud crying $\left(\chi^{2}=23.438, \quad \mathrm{P}<0.001\right)$, changing of facial expressions $\left(\chi^{2}=12.539, \mathrm{P}<0.001\right)$, complaining $\left(\chi^{2}=12.100, \mathrm{P}<0.001\right)$ and screaming $\left(\chi^{2}=12.539, \mathrm{P}<0.001\right)$ were significantly higher in the control group than in the experimental group. In addition, other behaviours such as an expression of fear $\left(\chi^{2}=8.533, \mathrm{P}<0.01\right)$, sensitivity $\left(\chi^{2}=12.907, \mathrm{P}<0.01\right)$ and grasping of objects $\left(\chi^{2}=8.100, \mathrm{P}<0.01\right)$ were significantly higher in the control group than in the experimental group. Uneasiness $\left(\chi^{2}=4.514, \mathrm{P}<0.05\right)$ and grasping movements $\left(\chi^{2}=4.103, \mathrm{P}<0.05\right)$ were also significantly higher in the control group than in the experimental group (Table 2 ).

Table 3 shows the severity of pain that mothers described according to the phases of labour. In the latent phase (ie, dilation of $2 \mathrm{~cm}$ ), the severity of pain was lower in the experimental group (VAS score $=1.75 \pm 0.71$ ) than in the control group (VAS score $=3.00 \pm 1.48)$. This difference was statistically significant $(t=3.38, \mathrm{P}<0.01)$. The pain severity expressed at $4 \mathrm{~cm}$ of dilation (control group VAS score $=6.35 \pm 1.42$, experimental group VAS score $=3.75 \pm 1.20, t=6.22, \mathrm{P}<0.001), 6 \mathrm{~cm}$ of dilation (control group VAS score $=8.35 \pm 1.08$, experimental group VAS score $=5.80 \pm 1.15, t=7.19, \mathrm{P}<0.001)$ and $8 \mathrm{~cm}$ of dilation (control group VAS score $=9.55 \pm 0.51$, experimental group VAS score $=7.85 \pm 1.22, t=5.72, \mathrm{P}<0.001)$ were all significantly lower in the experimental group than in the control group. When dilation reached $10 \mathrm{~cm}$, the pain severity was significantly lower in the experimental group (VAS score $=9.15 \pm 0.93$ ) than in the control group (VAS score $=10.00, t=4.02, \mathrm{P}<0.01$ ).

Table 4 shows the mothers' feelings about labour pain, and labour room and delivery procedures in the postpartum period. Mothers in the experimental group had more positive feelings about their deliveries $(40 \%)$ than those in the control group (5\%). Ninety-five per cent of mothers in the control group and $60 \%$ of mothers in the experimental group had negative feelings about their deliveries. Mothers in the experimental group had significantly more positive feelings 
TABLE 3

Comparison of visual analogue scale (VAS) scores between control and experimental groups

\begin{tabular}{|c|c|c|c|c|c|c|}
\hline \multirow[b]{2}{*}{ Dilatation period } & \multicolumn{2}{|c|}{ Control group $(n=20)$} & \multicolumn{2}{|c|}{ Experimental group $(n=20)$} & \multirow[b]{2}{*}{$t$} & \multirow[b]{2}{*}{$\mathbf{P}$} \\
\hline & VAS score & SD & VAS score & SD & & \\
\hline Latent phase $(2 \mathrm{~cm})$ & 3.00 & 1.48 & 1.75 & 0.71 & 3.38 & 0.002 \\
\hline Active phase $(4 \mathrm{~cm})$ & 6.35 & 1.42 & 3.75 & 1.20 & 6.22 & 0.000 \\
\hline Active phase $(6 \mathrm{~cm})$ & 8.35 & 1.08 & 5.80 & 1.15 & 7.19 & 0.000 \\
\hline Passing phase $(8 \mathrm{~cm})$ & 9.55 & 0.51 & 7.85 & 1.22 & 5.72 & 0.000 \\
\hline Passing phase $(10 \mathrm{~cm})$ & 10.00 & 0.00 & 9.15 & 0.93 & 4.02 & 0.001 \\
\hline
\end{tabular}

\section{TABLE 4}

Comparison of mothers' feelings towards the birthing process for control and experimental groups

\begin{tabular}{|c|c|c|c|c|c|c|c|c|}
\hline Feelings after the birth & \multicolumn{2}{|c|}{$\begin{array}{c}\text { Control group } \\
(n=20)\end{array}$} & \multicolumn{2}{|c|}{$\begin{array}{l}\text { Experimental group } \\
(n=20)\end{array}$} & \multicolumn{2}{|c|}{$\begin{array}{c}\text { Total } \\
(n=40)\end{array}$} & $\chi^{2}$ & $\mathbf{P}$ \\
\hline \multicolumn{9}{|l|}{ Labour pain } \\
\hline Negative & 19 & 95.0 & 12 & 60.0 & 31 & 77.5 & & \\
\hline \multicolumn{9}{|l|}{ Labour room } \\
\hline \multicolumn{9}{|l|}{ Delivery process } \\
\hline Positive & 3 & 15.0 & 2 & 60.0 & 15 & 37.5 & 6.827 & 0.08 \\
\hline Negative & 17 & 85.0 & 8 & 40.0 & 25 & 62.5 & & \\
\hline
\end{tabular}

about labour pain than mothers in the control group $\left(\chi^{2}=5.161, \mathrm{P}<0.05\right)$. The women in the experimental group had more positive feelings about the labour room $(65 \%)$ than in those in the control group (20\%). Negative feelings were expressed in $80 \%$ of the control group and $35 \%$ of the experimental group. The number of women who found their experience in the delivery room to be 'positive' was higher in the experimental group than in the control group. Negative experiences were expressed by $85 \%$ of mothers in the control group and $40 \%$ of mothers in the experimental group. The difference in pain expressions between the two groups was statistically significant $\left(\chi^{2}=6.827, \mathrm{P}<0.01\right)$

\section{DISCUSSION}

Mothers who received education about labour and nonpharmacological pain control methods and nursing care expressed significantly lower labour pain levels than mothers who did not. At all stages, the severity of labour pain was lower in the the experimental group, especially as dilation progressed.

For most of the women in the present study, labour pain was an acute and severe experience. The severity of labour pain obtained using the VAS was found to increase as dilation progressed. VAS was first introduced and used by Bond and Pilowsky in 1966 (18). Robinson et al (19) demonstrated that VAS was reliable in measuring the severity of pain. VAS is a sensitive method for evaluating pharmacological and nonpharmacological treatments and has a high correlation with verbal and numerical pain scales (20-22). Several studies have reported that the severity of labour pain obtained using VAS is low in the first half of the dilation period $(2 \mathrm{~cm}$ to $5 \mathrm{~cm})$ and high in the second half $(6 \mathrm{~cm}$ to $10 \mathrm{~cm})(23,24)$. In addition, it has been reported that mothers who receive support during labour have lower pain scores. Gençalp (7) measured the severity of pain using VAS once at the end of labour and found that mothers who did not receive nursing support in labour gave high point scores for the pain they experienced.

Chang et al (11) demonstrated that the levels of pain and anxiety in mothers was significantly reduced in experimental group mothers who performed massaging when compared with control group mothers. They also reported that massaging was an important nursing initiative, enabling mothers to cope with labour pain (11). Field et al (12) observed that massage performed during labour resulted in decreases in depression, anxiety levels and postpartum depression levels in mothers. Simkin and O'hara (10) reported that touching and massaging during labour were effective in coping with labour pain, especially with back pain.

The mothers observed in the present study showed emotional reactions previously mentioned in the literature. Some characteristics, such as loud crying, changing facial expressions, complaining, screaming, expressions of fear, sensitivity, grasping of objects, uneasiness and fisting were lower in the experimental group; mothers in this group were better able to cope with such negative feelings. Gençalp reported that characteristics such as a tendency to avoid staying alone, uneasiness, crying loudly, crying quietly, lip biting and screaming were less prominent in the experimental group than in the control group (7).

Some studies in the literature have suggested that allowing mothers an opportunity to express themselves and encouraging them during the pain period could lower the perception of pain. Thus, it is essential for mothers to be allowed to express their distress $(6,7)$. In our study, we explained to the mothers in the experimental group that their emotional reactions were totally normal, and encouraged them to freely express their 
feelings. Thus, it was thought that the education and support provided regarding nonpharmacological pain control methods (breathing and skin stimulation) were effective in lowering emotional reactions toward the delivery and helped patients cope with negative reactions.

Asti and Yildiz (25) found that therapeutic touching along with psychological support provided by the nurse could lower the anxiety of pregnant women who had suffered pain in the labour room. Guler (4) compared a group of mothers that received help in preparation in the predelivery phase with another group of mothers that did not receive any instruction or help in preparation. Guler found that anxiety was lower in the group with preparation. Several studies describe how mothers in labour believed that the emotional support provided by the nurses was the most important aspect of the nurses' activities $(2,3,26,27)$.

In the literature, labour pain is defined as very painful and hurtful $(7,26)$. Gençalp (7) reported that more than one-half of the mothers that received nursing support and those mothers that did not receive such support expressed labour as very difficult and painful. The findings of the present study demonstrated that the group receiving nursing support had more favourable thoughts about labour pain, emphasizing the importance of nursing care.

Delivery in a setting that mothers trust and feel safe in enables them to experience lower stress and anxiety, diminishing some of the issues that influence a mother's psychology. Mothers in the experimental group who received continuous supportive nursing care while in the labour room had more positive impressions about the labour room. In the literature, it has been observed that mothers who are together with many other mothers and observe their reactions to pain are negatively influenced $(3,7)$. Gençalp (7) observed that, although mothers who received nursing support found the labour room less complicated and terrible than those who did not, the majority of mothers felt that their experiences in the labour room were negative.

\section{CONCLUSIONS}

The present study aimed to demonstrate the effectiveness of education and nursing support at lowering mothers' perception of labour pain and helping them cope with it. The results of our study showed that, although pregnant women come to the labour room unprepared and the settings of the room often cannot be altered or corrected, education and nursing support for labour and nonpharmacological pain control methods enable mothers to adapt to labour more effectively, and are instrumental in facilitating more favourable delivery experiences. Therefore, supportive nursing care should be provided in maternity units.

\section{REFERENCES}

1. Lowe NK. The pain and discomfort of labor and birth. J Obstet Gynecol Neonatal Nurs 1996;25:82-92.

2. Kintz DL. Nursing support in labor. J Obstet Gynecol Neonatal Nurs 1987;16:126-30.

3. Kizilkaya N. [The thoughts of women related to supportive nursing behavior in labour]. Perinatoloji Dergisi 1997;5:213-6.
4. Guler K. [Research on anxiety differences in intrapartum and postpartum periods between pregnant women who were prepared for delivery physiologically and psychologically and pregnant women who were not]. Unpublished doctoral dissertation, University of Istanbul, Turkey, 1982.

5. Green JM. Expectations and experiences of pain in labor: Findings from a large prospective study. Birth 1993;20:65-72.

6. Gorrie TM, McKinney ES, Murray SS. Clinical manual for foundations of maternal-newborn nursing. Philadelphia: WB Saunders Company, 1994.

7. Gençalp NS. [The effect of supportive nursing care that is given to mothers in labour on delivery process]. Hemsirelik Formu 1999;2:109-13.

8. Reeder SJ, Martin LL, D Koniak-Griffin. Maternity Nursing: Family, Newborn, and Women's Health Care, 18th edn. Philadelphia: Lippincott Williams \& Wilkins, 1996.

9. Spiby H, Slade P, Escott D, Henderson B, Fraser RB. Selected coping strategies in labor: An investigation of women's experiences. Birth 2003;30:189-94.

10. Simkin PP, O'hara M. Nonpharmacologic relief of pain during labor: Systematic reviews of five methods. Am J Obstet Gynecol 2002;186(Suppl 5):S131-59.

11. Chang MY, Wang SY, Chen CH. Effects of massage on pain and anxiety during labour: A randomized controlled trial in Taiwan. J Adv Nurs 2002;38:68-73.

12. Field T, Hernandez-Reif M, Taylor S, Quintino O, Burman I. Labor pain is reduced by massage therapy. J Psychosom Obstet Gynaecol $1997 ; 18: 286-91$.

13. Keenan P. Benefits of massage therapy and use of a doula during labor and childbirth. Altern Ther Health Med 2000;6:66-74.

14. Hodnett ED, Gates S, Hofmeyr GJ, Sakala C. Continuous support for women during childbirth. Cochrane Database Syst Rev 2003:CD003766

15. Kardong-Edgren S. Using evidence-based practice to improve intrapartum care. J Obstet Gynecol Neonatal Nurs 2001;30:371-5.

16. National Population and Health Research 1998 (TNSA 1998). Ankara: Turkish Ministry of Health, General Directorate of Maternity-Child Health and Family Planning and Hacettepe University Institute of Population Studies, 1999.

17. Gungoren A, Bayhan G, Ozyilmez MA, Yayla M. [The effects of epidural analgesia on the process of birth]. İstanbul Jinekoloji ve Obstetri Dergisi 1998;2:81-5.

18. Bond MR, Pilowsky I. Subjective assessment of pain and its relationship to the administration of analgesics in patients with advanced cancer. J Psychosom Res 1966:10:203-8.

19. Robinson JO, Rosen M, Evans JM, Revill SI, David H, Rees GA. Self-administered intravenous and intramuscular pethidine. A controlled trial in labour. Anaesthesia 1980;35:763-70.

20. Cline ME, Herman J, Shaw ER, Morton RD. Standardization of the visual analogue scale. Nurs Res 1992;41:378-80.

21. Macky MC, Stepans ME. Women's evaluation of their labour. BIRTH 1999;26:9-10.

22. Raj PP. Practical Management of Pain, 2nd edn. St Louis: Mosby Year Book, 1992.

23. Bonnel AM, Boureau F. Labor pain assessment: Validity of a behavioral index. Pain 1985;22:81-90.

24. Brown ST, Campbell D, Kurtz A. Characteristics of labor pain at two stages of cervical dilation. Pain 1989;38:289-95.

25. Asti N, Yildiz A. [The effect of therapeutic touch on the perception of pain and situational anxiety that performed on pregnant women in labour room]. Konsultasyon-Liyezon Psikiyatrisi Kongresi, Istanbul, Turkey 1994:265-71.

26. Sheiner EK, Sheiner E, Shoham-Vardi I, Mazor M, Katz M. Ethnic differences influence care giver's estimates of pain during labour. Pain 1999;81:299-305.

27. Bryanton J, Fraser-Davey H, Sullivan P. Women's perceptions of nursing support during labor. J Obstet Gynecol Neonatal Nurs $1994 ; 23: 638-44$ 


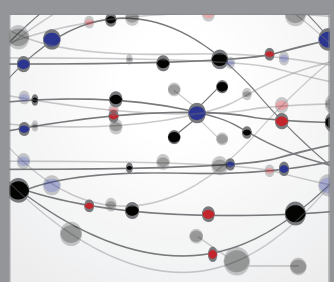

The Scientific World Journal
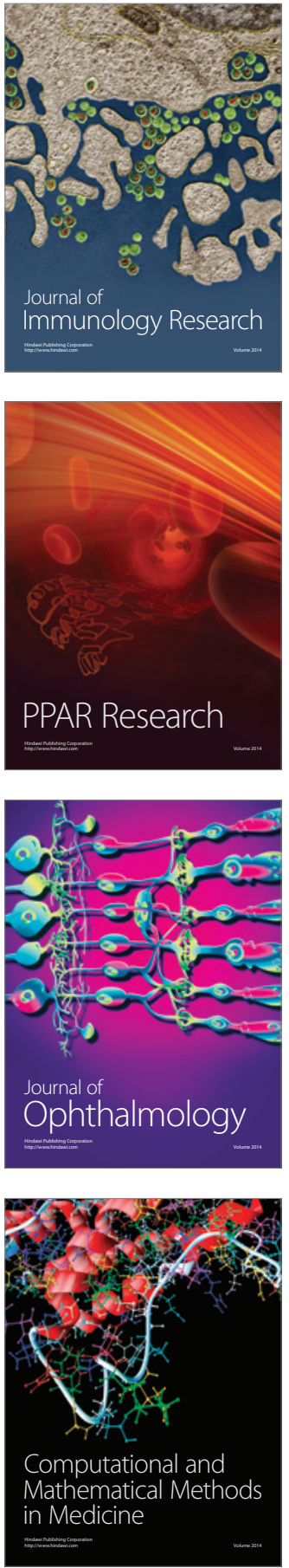

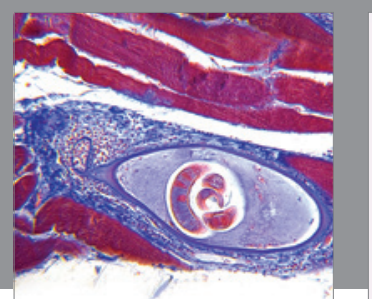

Gastroenterology Research and Practice

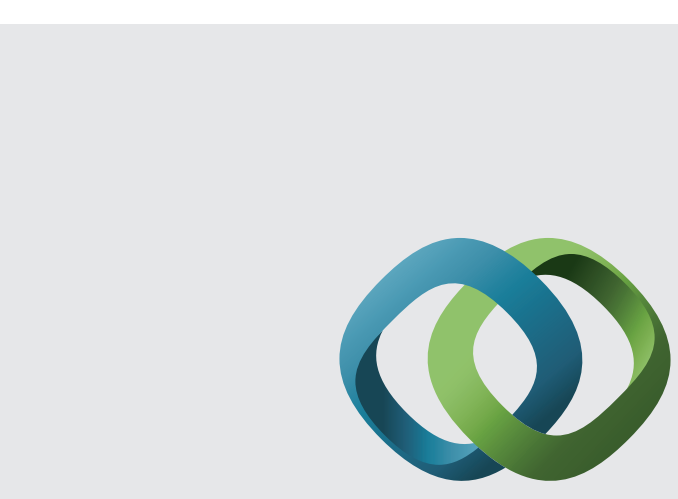

\section{Hindawi}

Submit your manuscripts at

http://www.hindawi.com
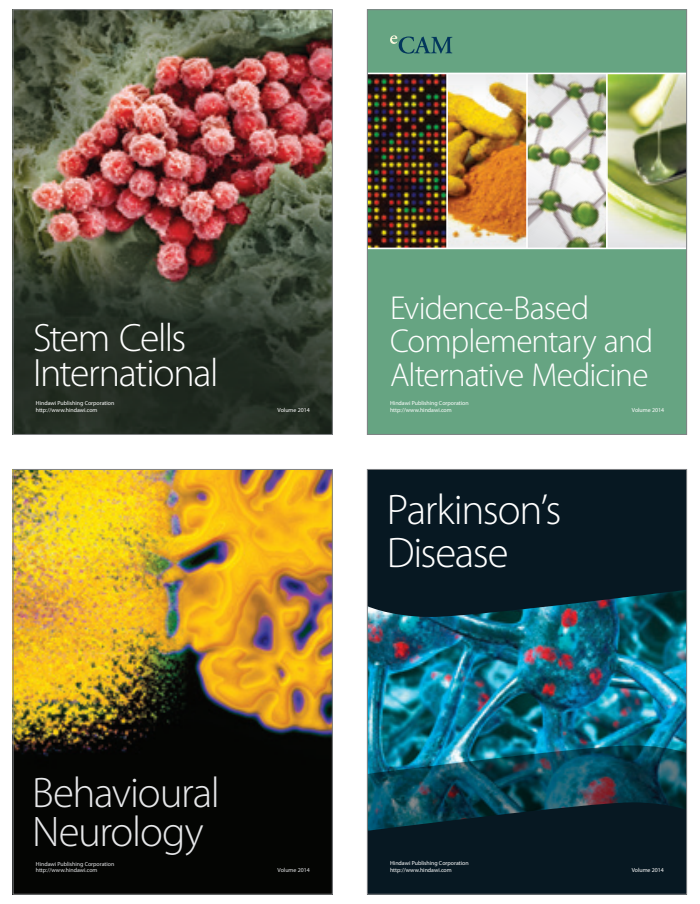
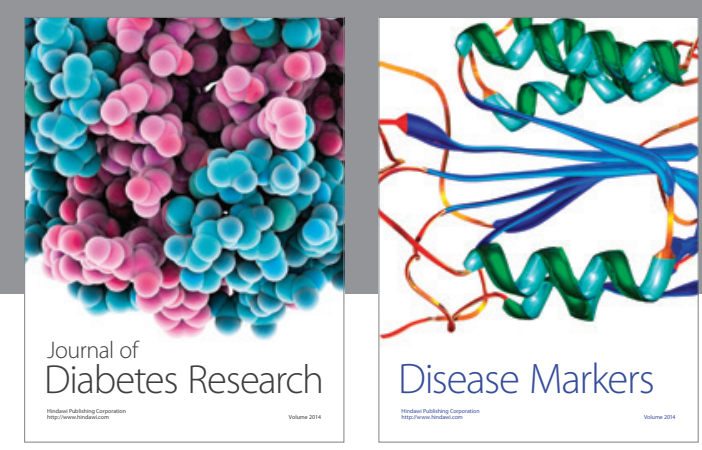

Disease Markers
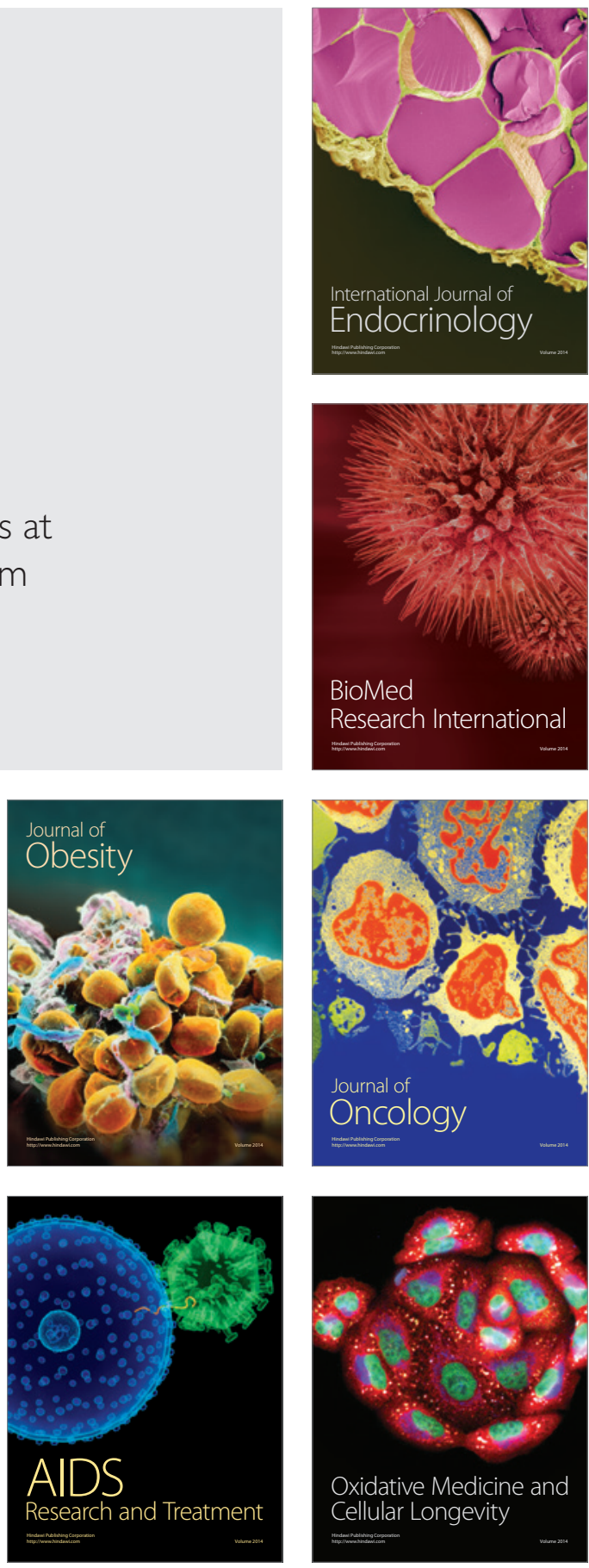